\title{
The Effect of Output Tasks on the Acquisition of English Verbal Morphemes
}

\author{
Shirin Abadikhah \\ University of Mazandaran, Iran \\ Email: sh_abadikhah@yahoo.com \\ Foroogh Zarrabi \\ University of Mazandaran, Iran \\ Email: forooghzarrabi@yahoo.com
}

\begin{abstract}
This paper aims to explore the facilitative effect of an output task on learning verbal morphemes by Iranian EFL learners. The main research question addressed whether engaging learners in output tasks can fill the gap between comprehension and production of verbal morphemes (present progressive-ing and simple past-ed) and promote learning of the target linguistic forms. Two groups of learners from young adult classes (all male students within the age range of 13-15) participated in the current study: an output group consisting of 20 learners and a control group consisting of 18 learners. All of them were administered a pretest and posttest. The learners in the output group worked on a text reconstruction task which employed an audio-text cartoon strip. The major findings were (a) the comparison of pre-test scores showed a significant difference between comprehension and production of target forms by the learners, (b) after receiving treatment, the output group outperformed the control group, (c) finally, the control group failed to show comparable improvement in their production although they had measurable gains in comprehending the target linguistic form. Considering the above findings, further support was found for the effect of output tasks on L2 learning. The findings contribute to the research that has examined type of task and level of processing in promoting $\mathrm{L} 2$ learning.
\end{abstract}

Index Terms —output tasks, verbal morphemes, reconstruction task

\section{INTRODUCTION}

Finding the most efficient way to teach grammar has been one of the most controversial issues in SLA over the past few decades (Celce-Murcia, 1991; Ellis, 2006). In search for the best way to teach grammar, the roles of input and output have received substantial attention in second language acquisition (SLA) theory and numerous studies have produced major insights in the field of SLA. Earlier studies gave the idea that acquisition is a natural outcome of comprehensible input (Krashen, 1985). Such studies have chiefly focused on the significance of comprehensible input in developing learners' knowledge of the target language. Lately, however, several studies have suggested that the role of output is as important (if not more) for acquisition of a second language as the role of input. These studies' claim is mainly based on Swain's output hypothesis (Swain, 1985) which considers output as the cause of L2 acquisition, not just the product of it. Studies on output (e.g. Dekeyser \& Sokalski, 1996; de la Fuente, 2006; Izumi, 1999; Izumi, 2002; Song \& Suh, 2008) together with formal and informal observations of Canadian immersion program (Swain, 1985) provide empirical evidence that developing productive ability of learners and language acquisition requires more than mere comprehending the language.

Many research findings to date have explored the role of output and different functions of it in language learning (Bygate, 1999; DeKeyser \& Sokalski, 1996; De la Fuente, 2006; Garcia Mayo, 2002; Geeslin, 2006; Izumi, 2002; Izumi \& Bigelow, 2000; Izumi et al., 1999; Izumi \& Izumi, 2004; Newton \& Kennedy,1996; Kim, 2009; Kuiken \& Vedder, 2008; Lyster, 2004; Mehrang \& Rahimpour, 2010; Mennim, 2003; Nobuyoshi \& Ellis,1993; Qin, 2008; Reinders, 2009; Shehadeh, 1999; Shehadeh, 2003; Song \& Suh, 2008; Storch,1998a \&1998b; Swain \& Lapkin, 1995; Vickers \& Ene, 2006; Yoshimura, 2006). Among the various functions of output proposed by Swain (1995), the noticing function has received substantial attention since many research findings show that noticing and attention play significant roles in language learning. Nevertheless, the studies which specifically have explored whether output tasks promote learning of target linguistic forms, as a result of noticing function, have produced mixed results (Izumi, 2002; Izumi \& Bigelow, 2000; Izumi et al., 1999; Izumi \& Izumi, 2004; Song \& Suh, 2008). Therefore, more research needs to be done to explore the issue. Besides, the possible effect of these tasks on learning grammatical morphemes has not been fully explored. This is despite the fact that many learners have problems in using these morphemes in natural settings particularly in expressing the notion of temporality through verbs. The present study is an attempt to tackle this issue. 


\section{A. Swain's Output Hypothesis}

As mentioned earlier, Swain (1985) considered an active role for output in L2 learning and believed that output is crucial to push learners to move from semantic processing to syntactic processing. She specified four functions for output: fluency, hypothesis testing, metalinguistic and noticing (Swain, 2005). Fluency function posits that by producing language in a meaningful context, learners can practice accessing L2 knowledge and as a result of recurrent practice, the speed of their access may increase. Another function of output is hypothesis testing function. Swain (2005) claimed that learners sometimes use their output to learn about the target language forms in a trial-and-error fashion. In other words, they use a target form and change it upon receiving feedback from their interlocutors. Modifying their output engages learners in processes believed to be part of the second language learning process (Swain, 2005). Metalinguistic function holds that we can use language to reflect on language, either produced by ourselves or by others. This act, swain claims, can mediate second language learning. Producing output - written or spoken - also provides learners with opportunities for noticing the problematic areas in their interlanguage. As a result, they may pay attention to the things they have to learn. This raised attention prompts the cognitive processes happening while the learner is learning a new "linguistic knowledge or attempts to consolidate the existing one" (Swain \& Lapkin, 1995, p. 384).

\section{B. Output as an Attention-drawing Device}

In light of the above theoretical arguments, several studies have empirically examined the role of output tasks in L2 learning (e.g. Colina \& Garcia Mayo, 2007; Dekeyser \& Sokalski, 1996; Izumi, 2002; Izumi \& Bigelow, 2000; Izumi et al., 1999; Izumi \& Izumi, 2004; Mennim, 2007; Nassaji \& Tian, 2010; Qin, 2008; Reinders, 2009; Song \& Suh, 2008; Swain \& Lapkin, 1995; Yoshimura, 2006). One of the first studies of this kind was Swain and Lapkin (1995), which attempted to provide support for the "noticing" function of output. They gave young learners a writing task and taperecorded their speech during task performance to check the cognitive processes involved in L2 learning. They found that young adult L2 learners do notice the gaps in their linguistic knowledge during language production and also engage in cognitive processes such as grammatical analysis believed to be effective for L2 learning. The role of output, especially its noticing function, was explored in other studies, too. Izumi, Bigelow, Fujiwara, and Fearnow (1999), for example, sought to explain whether an output task encourages the noticing of the past hypothetical conditional in English through two different tasks. In the first stage of the task, the output group had to remember and reconstruct a passage but the input group had to answer true /false questions on the same passage. In the second stage of the task, the output group had to revise what they have reconstructed while the input group had a free-writing activity in which the use of the target form was not required. The result of the study supported the output hypothesis partially in the sense that the difference between the two groups was statistically significant only on posttest of production for the second stage of the task but not for the first one. The researchers believed that this was because in the first stage of the task the output group had to remember and reconstruct the passage at the same time which was of great memory demand and prevented the participants to concentrate on the target form. Izumi and his colleagues concluded that beside considering how the task encourages noticing, we should take into account how it encourages further processing after noticing has taken place. Izumi and Bigelow (2000) conducted a similar study but found no improvement for the experimental group on any of the posttests- neither on the recognition test nor on the production test. In an attempt to revise the previous studies, Izumi (2002) conducted another study in which he found that the participants who took part in the output treatments showed greater improvement in learning the target form than the learners who received the same input just for comprehension. In the next study, Izumi and Izumi (2004) changed the modality of the output task and investigated the effect of oral output on the acquisition of relative clauses in English. The output group engaged in a picture description task while the non-output group engaged in a picture sequencing task. The two treatment groups were exposed to the same aural input for the same amount of time. Contrary to the expectations, the results illustrated that the output group did not outperform the non-output group while the non-output group demonstrated greater overall language gains. A careful post-hoc reconsideration of the treatment tasks showed that the output task failed to engage learners in the syntactic processing required for triggering L2 learning, whereas the task for the non-output group seemed to encourage form-meaning mapping better.

While most researchers were interested in finding the effects of engaging learners in output tasks on noticing and learning, Yoshimura (2006) examined the effect of foreknowledge of output tasks on noticing and processing of input. Put it simply, he told the participants they were going to engage in three types of tasks: exact reconstruction in which they had to memorize the text for later reproduction, content reconstruction in which the participants had to retell the content of the text and finally, reading for visualization (control task) during which they had to draw a picture based on the reading text. The interesting point was that, at the end of the study, instead of performing output tasks, learners took a posttest of comprehension and fill in the blanks. Yoshimura expected the participants to notice the gap in their interlanguage through the first two tasks. The analysis of the data suggested that the production groups were more successful in verb uptake than the control group. Yoshimura concluded that noticing of the language can happen not only during or after the output task but also before production of output if the learners consider input processing as a planning stage for subsequent output tasks.

Mennim (2007) also explored long-term effects of noticing on oral output. He reported on the effects of classroom exercises that promote noticing and conscious attention to form. During an academic year, records of the learners' 
output were carefully examined for noticing and improvement in the use of the noticed forms. Initial analysis of the tracking of two students' noticing and subsequent use of the form revealed that they had much difficulty at the beginning of the year but nine months later, they showed much improvement in using the form accurately. Through this study, Mennim attempted to show how learners' noticing of the word might be related to this improvement.

\section{The Effect of Output Task Types}

A few studies have also compared the effectiveness of different kinds of output tasks on noticing and learning of target forms. Swain and Lapkin (2001), for example, engaged immersion students in two tasks i.e. a jigsaw task and a dictogloss task. They asked their students to reconstruct a content which was the same for the two tasks. The researchers hypothesized that the dictogloss task would foster greater attention to form. Contrary to their expectations, task differences did not lead to greater attention to linguistic forms. However, dictogloss students were more accurate than jigsaw students. In addition, dictogloss students attended to discourse structure but jigsaw students did not focus on logical and temporal sequencing. Furthermore, dictogloss students produced more complex linguistic structures and vocabulary. Colina and Garcia Mayo (2007) also examined the effectiveness of three types of output tasks: a text reconstruction task, a jigsaw task and a dictogloss task. The study showed the efficiency of all these tasks in drawing learners' attention to form. However, findings of the study seem to indicate that task type controls the nature of attention. That is, different tasks draw learners' attention to different features of language. For example, the text reconstruction task focused learners' attention especially on determiners, passive voice and verb form while jigsaw task focused their attention on a wide variety of linguistic features. Besides, the findings of their study indicated that the text reconstruction task caused the greatest attention to form. On the other hand, Song and Suh (2008) who compared the effectiveness of a reconstruction task with a picture-cued writing task in noticing and learning of English past counterfactual conditional reported that the efficacy of the two output tasks was the same in the posttest. In line with the study of Song and Suh (2008), Reinders (2009) explored the effects of three types of production activities on uptake and acquisition of negative adverbs in English. He found that the effect of the three activities - a dictation, an individual reconstruction and a collaborative reconstruction task - was almost the same on the acquisition of grammatical items. The result suggested that all three activities led to uptake. However, the collaborative reconstruction and the dictation activities resulted in greater uptake than the individual reconstruction activity.

While Song and Suh (2008) and Reinders (2009) reported no considerable effect of task type on learning, Nassaji and Tian (2010) reported significant effect in their study. They compared the efficiency of reconstruction cloze tasks and reconstruction editing tasks in learning English phrasal verbs. Furthermore, they examined the effect of performing the tasks collaboratively versus individually. The results revealed that accuracy of task completion was greater when learners completed the tasks collaboratively comparing with the time they completed them individually. However, collaborative tasks did not result in considerably greater gains of vocabulary knowledge than individual tasks. More importantly, the results suggested an effect of task type as the editing task was more effective than the cloze task in promoting negotiation and learning.

One conclusion that may be drawn from the above studies is that output tasks may facilitate noticing of the target forms, but they may not necessarily lead to better gains of knowledge in comparison to non-output tasks. Nevertheless, as Song and Suh (2008) stressed, studies in this area did not show a clear positive effect for noticing function of output. Besides, contradictory results were reported on the effect of text reconstruction task on the learning of target forms. Based on the foregoing discussion, the present study addressed the following research questions:

1. Would there be a difference (or gap) in the performance of the Iranian young adult EFL learners between their comprehension and production of verbal morphemes (present progressive -ing and simple past -ed)?

2. If it is so, would output task (i.e., text reconstruction task) fill the gap between comprehension and production of verbal morphemes (-ing and -ed) by Iranian young adult EFL learners?

3. Would output task affect Iranian young adult EFL learners' acquisition of verbal morphemes?

\section{METHOD OF THE STUDY}

\section{A. Participants}

The participants were chosen from among students (within the age range of 13-15) enrolled in the Iran Language Institute (Babol branch), an important language institute in Iran. The two selected classes were similar in their level and student population. The selection of the participants was based on the results of the pre-test on the target forms. The participants who demonstrated an acceptable knowledge of the target linguistic forms but had yet to improve their knowledge of the morphemes were invited to participate. During the pre-test, those students who showed sufficient knowledge of the aforementioned morphemes (scored $90 \%$ or above) and those who did not demonstrate any sign of knowledge of these morphemes both in their comprehension and production were eliminated from the participants' pool Thirty-nine out of forty two students who participated in this study were assumed to be developmentally ready to learn the target form. All of these students agreed to participate in the study. One group was randomly chosen as the control group and the other one as the experimental group.

\section{B. Procedure}


The procedure of the study was as follows: first, one of the researchers administered the pretest and scored the test papers in each class to screen the participants meeting the requirements of the study. The pretest was conducted in three sessions - one session for comprehension test and the next two sessions for production tests all of which were in written modality. Two production tests were given to the learners to check their production of verbal morphemes both in and out of context. The reason for using two production tests was that the researchers were interested in checking the learners' production at sentence and discourse levels. The interval between the pretest and the first practice session was exactly one week. The practice sessions were also in written mode and included three successive sessions with a oneweek interval between them. The students were told that the purpose of the study was to help them make progress in English writing. Before beginning the first session, the participants were made familiar with the procedures of the practice sessions. After the practice sessions, the posttest was administered in three sessions with the same order as employed in the pretest. There was a one-week interval between the last practice session and the first session of the posttest.

\section{Instructional Treatment}

\section{Text reconstruction task}

The task used in this study was a modified version of a text-reconstruction task used in previous studies on output. The whole treatment was done using an audio-text cartoon strip from a series published by Oxford University Press (Toyama \& Rivers, 2005). The input was controlled for length, which helped the researchers have full control over the time of input exposure and succession of the activities which eventually made data collection easier. This cartoon strip was specially selected because it was expected to be reasonably, though not intimately, familiar to the participants. It was also expected that the content would constitute a feasible processing load in terms of understanding for the learners. After all, the story was suitable for the purpose of the study as it consisted of two parts: present and past. Following Izumi (2002), the whole text was divided into two parts to lighten the memory load on the learners. Then, the learners had to read and listen to two two-minute audio texts which were semantically related to each other. The pausing point was carefully chosen so that each part remained coherent and meaningful. There were about 20 sentences in each part so it was neither very long for the learners to forget the content of the story nor very short to memorize the sentences. An important modification in this text reconstruction task was the cartoon- strip accompanying audio-texts. The cartoon strip seemed to lighten the memory load on the part of the subjects when they were reconstructing the texts and to help them concentrate on the form rather than on recalling the story line. Audio text was selected instead of common texts, again to help the learners in reading, and as a result, to provide them with more time and attentional resources to devote to forms. The text was not artificially made for this task. Rather, it was an authentic text to give learners a chance to prepare for confronting with genuine texts in real life situation. Furthermore, the text was carefully selected to have sufficient amount of target forms to attract learners' attention.

\section{Treatment procedure}

At first, the goal of the task was conveyed to the learners in the output group. They were told to a) read and listen to the story carefully and try to understand it and b) reconstruct the text as accurately as possible. Then, the emphasis was on comprehension so that the real aim of the study does not become clear to the participants. Before beginning the task, the participants were told that they have to read and listen to the audio text carefully because it will not be repeated for them before they reconstruct it for the first time. They were instructed not to take any notes during input exposure phase. They were also informed in advance that they will have limited amount of time for production to account for time variable. After the first input exposure, the learners had to reconstruct the text as accurately as possible. Similar procedure was adopted and employed in the second and third sessions. When the learners reconstructed the whole text, the same procedures were repeated. At this point, the learners were instructed to make any changes they thought necessary to make their written productions as accurate as possible. Again, the learners were not allowed to take notes during input exposure. The same procedures were followed for the second input exposure. No feedback was given before or during the study about tasks or students' performance so that only purely task-based effects are gathered.

\section{Testing Instruments}

To assess learners' knowledge of the target forms before and after the treatment, three different testing measures were used. A multiple choice test of verbal morphemes was used to check receptive knowledge of the forms. To check their productive knowledge of the target forms, first, an individual picture description task was used. Next, a picturedescription task in context was employed which included two parts: one aimed at testing learners' production of -ing morpheme (present progressive tense) and the other for testing their production of -ed morpheme (past tense). The tests were given in the order mentioned above. Equal number of items was allocated for each of the targeted morphemes in each test. In the context picture-description task, the number of items was also equal but each of them was aimed at specifically testing one of the morphemes. The exact time for each test was determined in advance based on the results attained from pilot studies. To avoid drawbacks of learners' fatigue due to taking several tests, the testing sessions were held separately- one test in each session in the above mentioned order (see Appendices A, B and C).

\section{Recognition test}

The recognition test consisted of 20 multiple choice items adopted from Bloor et al. (1970) (see Appendix A for sample items of the recognition test). Half of these items were to check learners' ability to recognize correct use of 
present progressive -ing and the other half was allocated to simple past -ed. The participants were instructed to choose one answer which is correct. One point was assigned for each correct answer and no point was given when they chose incorrect answers or gave no answer. Then, the total score for all items answered correctly was 20 .

\section{Individual picture description task}

Following Sung and Suh (2008), the individual picture description task was employed in the study (see Appendix B for sample pictures of the individual picture description task). The pictures were adopted from Toyama and Rivers (2005) published by Oxford University Press. In the present study, this test was used as a written elicitation measure to assess learners' productive knowledge of target forms. For each item in this test, learners saw the picture and described it in a simple sentence. In each picture, the time was clearly mentioned. The learners were asked to pay attention to the time mentioned in each picture and try to use it in their sentences. The test included 20 items and the time allocated for each item was one minute. Decisions about the time for each exam were made based on feedback received from the pilot studies.

\section{Picture description task in context}

The picture description task in context was specially made for this study as the researchers were interested in assessing the learners' ability to use verbal morphemes in context where discourse rather than isolated sentences was the unit of producing language. Two pictures were selected for this purpose- one indicating time in the past and the other one indicating present. The activities the characters were doing in each picture were numbered. Thus, the learners were expected to produce eight sentences for each picture. We thought that the learners might produce more than eight sentences for each picture since they were going to write at discourse level, but in scoring, just those eight items were taken into account for each picture. So, they had to produce at least sixteen items for the two pictures.

\section{E. Scoring and Analysis}

All the test data were scored by giving one point to a correct answer and zero for an incorrect answer. The data from each test were scored separately. Owing to differences in the number of items included in each test, scores obtained from each testing measure were changed into percentage. Finally, the composite score was calculated using the results of all three testing measures. It is worth mentioning that the composite score for the two production tests was also obtained to have a clear idea of output tasks on learners' productive knowledge. On all production tests, only the production of the targeted morphemes was considered as correct response. The errors related to spelling were ignored since the researchers were only concerned about using correct morphemes for the related tense.

\section{RESULTS}

To answer the research questions, the statistical analysis of SPSS was performed to determine 1) whether there is a difference between the learners' recognition and production tests of verbal morphemes, 2) whether there is any significant difference between the two groups concerning their performance after the practice sessions and finally, 3) whether there are any significant changes within groups regarding their receptive and productive abilities over time. Before examining the effect of treatment, the knowledge of the two groups on the past and present progressive morphemes was examined. To do so, the composite test scores of the two groups on pretests of comprehension and production were submitted to independent-samples t-tests. It should be noted that the data from each testing measure were scored separately and were then combined to obtain a composite test score. The result of the analysis illustrated no significant difference on the knowledge of verbal morphemes (their comprehension and production) between the output group $(M=54.93, S D=15.96)$ and the control group $(M=48.29, S D=15.13)(d f=36, F=.000, p<.05)$. Therefore, any difference between these groups on posttests or any gains from pretest to posttest can be attributed to the effect of the treatment.

\section{A. The Difference between Comprehension and Production of Verbal Morphemes}

Our first research question addressed whether there is a difference between comprehension and production of verbal morphemes (present progressive -ing and simple past -ed) by Iranian young adult EFL learners. The test results revealed a large gap between the mean scores of the learners obtained on recognition test and production tests, in the sense that they did considerably better on comprehension test than on production tests. To examine the statistical significance of the issue, the mean score of the comprehension test was compared with the mean composite score of the two production tests. The result of the comparison through a matched t-test indicated that there is a significant difference between the learners' comprehension and production of verbal morphemes $(\mathrm{df}=37, \mathrm{t}=14.77, \mathrm{p}<.05)$.

\section{B. The Effect of the Output Task on the Gap between Comprehension and Production}

The second research question addressed whether employing an output task would fill the gap between comprehension and production of verbal morphemes. To find an answer for this question, the difference between the learners' mean scores on comprehension test and production tests was computed on both their pretest and posttest separately and then, the difference obtained for posttest was subtracted from that of pretest. In this way, the amount of the gap remained as a result of the production task was computed. Table 1 presents the descriptive statistics for the mean scores of the output group on all tests before and after the practice sessions. 
TABLE 1

DESCRIPTIVE STATISTICS FOR RECOGNITION AND PRODUCTION TEST SCORES FOR THE OUTPUT GROUP

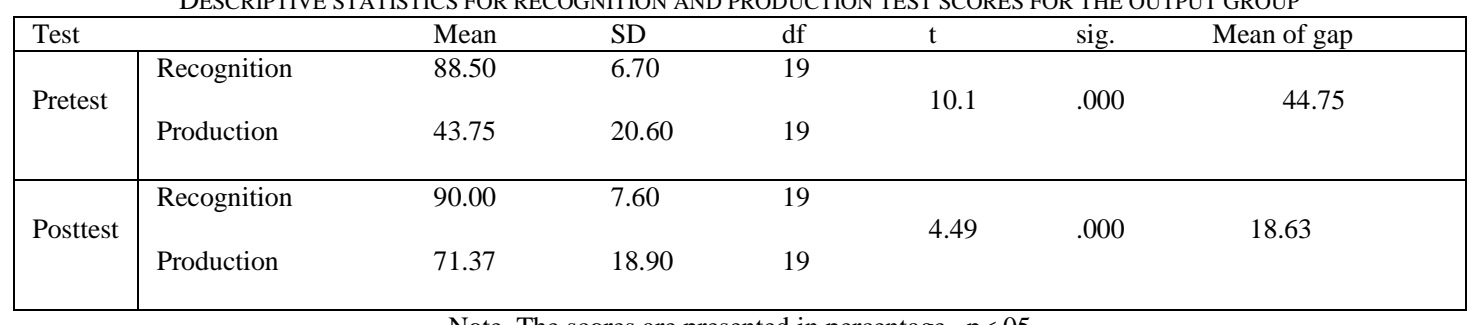

Note. The scores are presented in percentage. $\mathrm{p}<.05$

As it is clear from the table, the output task had major effect on filling the gap between the learners' comprehension and production of the target form. However, the remained gap was also considerable. In other words, although the output task was very effective in filling the gap between the learners' receptive and productive knowledge of the verbal morphemes, it did not live up to the expectation the researchers had based on psycholinguistic rationale of the output hypothesis.

To explore the statistical significance of the change brought about by the output task, the mean score of the comprehension test was compared with the mean score of the two production tests, on both pretest and posttest, using a matched t-test. This analysis was done for both pretest and posttest so that the statistical significance of the gap on both tests is compared. The result of the analysis showed that there was a significant difference between the learners' receptive and productive knowledge of verbal morphemes $(\mathrm{df}=19, \mathrm{t}=10.01, \mathrm{p}<0.05)$, and the difference remained statistically significant even after the practice sessions $(\mathrm{df}=19, \mathrm{t}=4.49, \mathrm{p}<0.05)$. However, the fact that the output task decreased this gap to a great extent cannot be denied.

\section{The Effect of the Output Task on the Acquisition of Verbal Morphemes}

The third research question addressed the effect of the output task on the acquisition of the target form. To find an answer to this question, the two groups were compared after the practice sessions. The overall test result indicated that the output group experienced greater improvement than did the control group since the increase in the mean score of the output group from pretest to posttest was around 21.09, which was considerably higher than the control group's gain (9.77). To test for the statistical significance of these differences, the posttest mean composite scores of the groups were computed and compared using independent samples t-tests. The result showed a significant difference in scores of the two groups $(\mathrm{df}=36, \mathrm{t}=3.06, \mathrm{p}<0.05)$, which indicated significant main effect for the output practice. In other words, the output task employed in this study was effective for acquiring verbal morphemes.

As a further test to detect whether the output group has made improvement, the mean scores on pretests and posttests were compared using a matched $t$-test. The result revealed that they had made significant improvement $(\mathrm{df}=19, \mathrm{t}=5.57$, $\mathrm{p}<0.05)$ from pretest to posttest.

\section{The Effect of the Output Task on Productive Knowledge of the Learners}

Though the comparison made between the mean scores on pretest and posttest for the output group showed positive effects of the output task, it did not provide detailed information on its effect on different aspects of their knowledge. This called for further analysis on different aspects of the participants' knowledge (i.e. receptive and productive). The result of preliminary analysis showed high achievement after practice sessions as the increase in the learners' production score from pretest to posttest was around 27.62. To gain detailed information on the issue, the mean scores obtained from the production tests in the pretest and posttest were compared using matched t-test. The analysis showed that the output group had significant improvement in their productive knowledge of the target forms after practice sessions $(\mathrm{df}=19, \mathrm{t}=5.49, \mathrm{p}<0.05)$. Interestingly, a comparative result was reported when the mean composite score of production pretest and posttest of the output group and the control group were compared using independent t-test.

The results also suggest that there is a significant difference in the scores of production tests between output group and control group $(\mathrm{df}=36, \mathrm{t}=2.47, \mathrm{p}<.05)$. This indicates that the participants engaged in output task gained higher achievement on tests of verbal morphemes than did the participants in the control group. Considering the obtained results, it is clear that the output task had a considerable impact on the production of verbal morphemes by the learners.

\section{E. The Effect of the Output Task on Receptive Knowledge of the Learners}

To examine the effect of output tasks on receptive knowledge of the learners, the mean scores of the comprehension test by the output group in the pretest and posttest was compared. The result of the analysis using a matched $t$-test indicated that there was no significant difference between the mean scores of comprehension test on pretest and posttest. This means that no significant increase in the learners' receptive knowledge of verbal morphemes can be associated with the output task $(\mathrm{df}=19, \mathrm{t}=.79, \mathrm{p}<0.05)$. Thus, not all testing measures showed strong positive effect for the output task. It appears that the beneficial effect of output task was limited to productive ability of the learners. And it may be concluded that the output group was successful in learning and balancing the difference between their comprehension and production of verbal morphemes to a great extent. The control group, on the other hand, failed to show as much 
learning of the form while their comprehension level was comparable to that of output group. This seems to be consistent with findings of previous studies which reported positive effects of output tasks on learning.

To present information on the magnitude of the treatment effect, the effect sizes were computed using 'Chen's d' which is a common effect size indicator for independent samples t-tests. The effect size is of great value to the study as it provides significant information on the effect of the practice sessions without being affected by the sample size of the study (Izumi, 2002). The result of analysis for Cohen's d was 1.01 for the total of one comprehension test and two production tests divided by three.

\section{DISCUSSION}

This study intended to explore two major questions: whether there is a gap between comprehension and production of verbal morphemes; and if so, whether an output task can fill this gap. Two major findings were reported in the current study. First, it was revealed that there is a significant difference between learners' scores on comprehension and production tests. Second, in terms of acquisition, it became evident that those engaged in the output task performed considerably better on posttest than did the learners in the control group. This finding reveals that having the chance of producing output in a meaningful way has positive effects in promoting learners' productive abilities on verbal morphemes.

Detailed analysis of pretest results suggested that there was a considerable difference between learners' performance on comprehension and production tests. While most of the learners achieved acceptable scores on comprehension test, many of them could not do well on production tests. Thus, it was concluded that there exists a gap between learners' comprehension and production of verbal morphemes. It is encouraging to compare this finding with a seminal study by Swain (1985). She found that in Canadian Immersion Program, there was a considerable gap between the learners' comprehension and production. This finding further supports the idea that providing learners with comprehensible input or even the existence of comprehended input is not adequate and will not guarantee automatic learning of the form present in the input.

Regarding the second research question, evidence to support the positive effects of producing output was observed in the posttest in the sense that the learners in the output group had significant gain in their productive knowledge of the target form. Considering the amount of gap in the pretest, the output task was successful in filling a great amount of it (almost 58\%); however, the remained gap cannot be ignored. There are several possible explanations for this result. Firstly, this result may be explained by the fact that time matters when the learners are engaged in an activity. The learners in the present study participated in three practice sessions. During this period, they succeeded in filling around $58 \%$ of the gap. It seems possible that the remained gap might be filled if more practice sessions were included in the study. The positive effect of output tasks in long run is also reported by Mennim (2007) who detected much improvement in the learners' accurate use of the target form nine months after the beginning of the study. Also, it is not unlikely that the learners might show even better gains on delayed posttest than on immediate posttest as was reported by De la Fuente (2006). It is also possible that this gap might never be filled totally and always may remain some superiority of learners' receptive knowledge over their productive knowledge. Since comprehending a message may be easier than producing it, more mistakes in the produced message may be observed which may finally show up in better performance in comprehension than in production. To comprehend a message, people do not necessarily employ their linguistic knowledge. In fact, some researchers (Clark \& Clark, 1977, cited in Izumi, 2003) claim that syntactic processing may be bypassed by the learners in comprehension processes and semantic or contextual cues may be used instead. In the process of production, based on Levelt's speech production model, learners have to go through different stages which are more demanding in quality, for example message generation, grammatical encoding and monitoring. So, it is not unusual to see that there remains a gap in favor of their comprehension. In general, this study has found that output, as an internal priming device, evidently worked well in promoting learning of the target forms. It succeeded in putting the learner in favorable situations which encouraged comparison between the forms in their interlanguage and the target language system.

The result of the analysis made on the means of overall test scores to detect the change happened within the output group also indicated that there was a significant gain for the output group. This prompted further analysis to detect the effect of the output task on the learners' receptive and productive knowledge separately. The details are as follows. The result of the analysis which compared the mean score of overall production test scores on pretest with that of posttest suggests that the output group had considerable gains on their productive knowledge of verbal morphemes after practice sessions. This is in line with Izumi (2002) and Song and Suh (2008) who reported similar effects on learners' productive abilities. It seems that providing learners to produce the target forms plays an important role in helping them notice the gaps in their interlanguage.

Though findings of the study indicate that the learners had considerable gains in productive abilities, no significant growth was found on the learners' gain scores on posttest of comprehension. This implies that output tasks may not be more effective than comprehension activities in promoting learners' receptive knowledge of the morphemes. As a result, it can be concluded that although output tasks had unique effect on development of learners' verbal morphemes, the effect was limited only to productive abilities and did not affect their receptive knowledge of the targeted forms to a considerable extent. This is exactly in contradiction with what Izumi (2002) found in his study. There, he found dual 
effect for output tasks on comprehension and production of English relativization for the output plus input enhancement treatment and interpreted it as the effect of output treatment on learners' interlanguage development. It is worth noting that the learners in his study were exposed to input enhancement which is a comprehension-based activity. On the other hand, our findings support the findings of Song and Suh (2008) that reported learners' gains in productive abilities but did not detect such effect on their receptive abilities.

The result of comparing the two groups' means suggests that the output group outperformed the control group on learning verbal morphemes at a statistically significant level. Following some studies reported in Norris and Ortega (2000), Cohen's d was calculated to compare the output group with the control group. It became evident that the effect size for the present study is quite large $(\mathrm{d}=.69)$ compared to the effect sizes obtained in Norris and Ortega's study for focus on form implicit treatments.

\section{CONCLUSION}

The results of the present study lend empirical support to the positive effect of output treatment on learning English verbal morphemes by young adult learners of English as a foreign language. Findings indicate that the output task had a significant effect on developing learners' acquisition of the verbal morphemes, particularly their productive knowledge of the forms. The first implication from the present study is that the output condition is very effective in increasing learners' noticing of the verbal morphemes. This is in line with research findings which state the importance of output tasks for learning (Swain, 1995; Izumi, 2002) and their significant roles in developing productive language skills (Anderson, 1996; de Bot, 1996; Song \& Suh, 2008).

This study may also have some implications for designing output tasks in educational setting. Findings of the present study indicate that the text reconstruction task had significant effect on improving learners' productive ability of verbal morphemes. This means that a challenging problem for learners, in target language grammar, was tackled quite easily within the possibilities of classroom setting. Participants were engaged in output tasks which provided them with the opportunity to do some syntactic processing and notice the problematic areas which was usually bypassed. It is worth noting that all these were achieved by using a content which constituted a feasible cognitive burden in terms of content words and untargeted function words, but posed major processing load in terms of target linguistic feature. This kind of output task can be used as a supplementary activity in English classroom since it can draw learners' attention to grammatical features of target language internally and keep their focus on content at the same time. When input-based activities (input-flooding), feedback, and unfocused activities (written or spoken) prove unhelpful, this sort of activity can be of great help by having two positive points: being focused and engaging learners in deep syntactic processing.

Nonetheless, the study suffers from some limitations. Firstly, it involved a very small sample size, which limits the generalizability of the findings. A larger sample size in future studies can be very helpful in promoting the external validity of the study and its generalizability. Secondly, due to time limitation, the study involved few treatment sessions. Conducting a study with more treatment sessions will illuminate the effect of these tasks in a more efficient way. Also, employing a delayed posttest would be desirable since it may show the effect of the task in the long run. In the present study, only one immediate post test was employed. A longitudinal study in future can account for these limitations by including more treatment sessions and delayed posttests. Future research can extend this study by examining the relationship between output task type and different linguistic forms. Also, further research is needed to explore possible effects of other output tasks in terms of complexity and cognitive factors (Robinson, 2001) on the noticing and learning of the target linguistic forms.

\section{APPENDICES}

A. Recognition test (Sample questions from the pre-/post-test)

1. Last night, Matt -------- a picture at the Amusement park.
A) have taken
B) take
C) were taking
D) took

2. What are you doing under the table? I -------- to find my pen.
A) tried
B)had tried
C)try
D)am trying

3. Many years ago, people ------------- dirty clothes with hands but today they use washing machines.
A) have washed
B) had been washing
C) wash
D) washed

4. Now Ted --------- a book about sharks. I don't think he will finish it.
A) reads
B) read
C) has read
D) is reading

5. When I was ten, I ------------ a beautiful bicycle.
A) have had
B) had
C)have
D) have been having

\section{B. Picture prompt for the picture-cued writing (Examples from the form used in the pre-/post-test)}




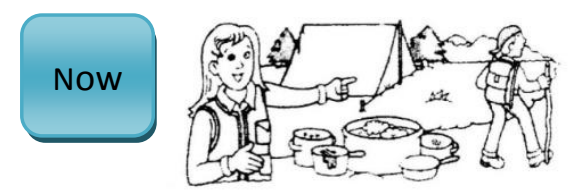

1. Climb a mountain
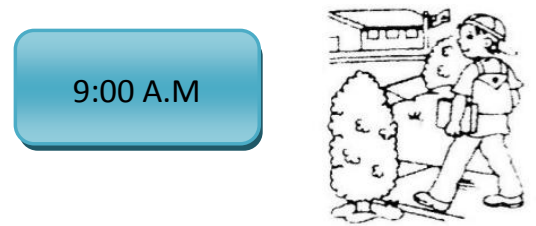

1. Walk to school

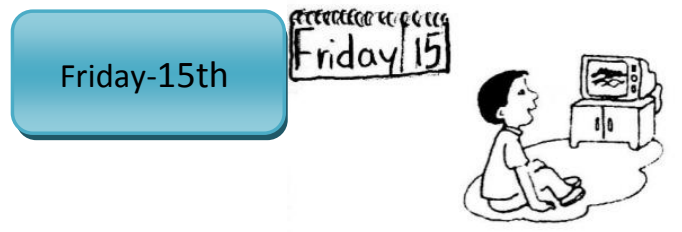

2. Watch TV
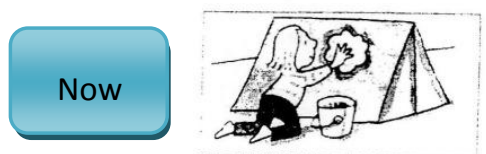

4. Clean the tent

C. Contextualized production test (Sample questions from the pre-/post-test)

Part I. look at the picture, consider the context and then try to describe the picture using at least 8 numbered items.

1. Last Saturday, Annie and her family and friends went on a picnic.

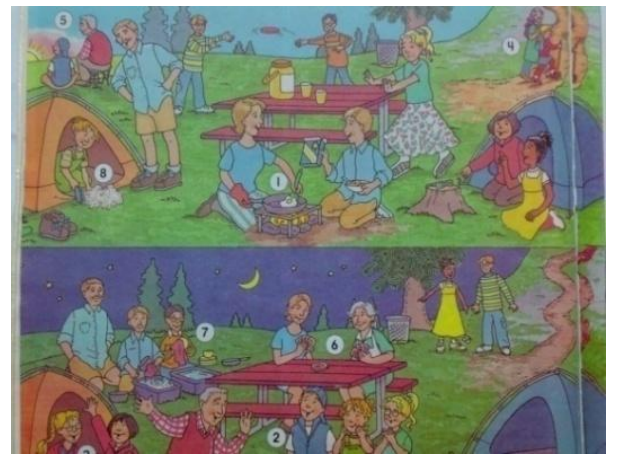

2. Today is Monday. Everyone is busy. The barber is cutting the little boy's hair.

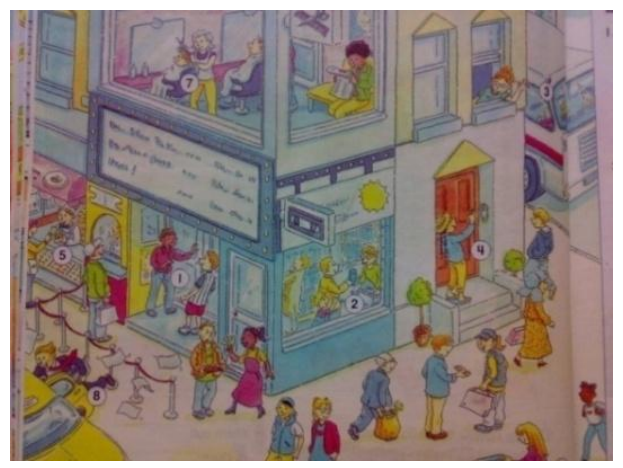


D. Picture cues and input passage for the reconstruction task (An example from the form used in the 1st treatment session).

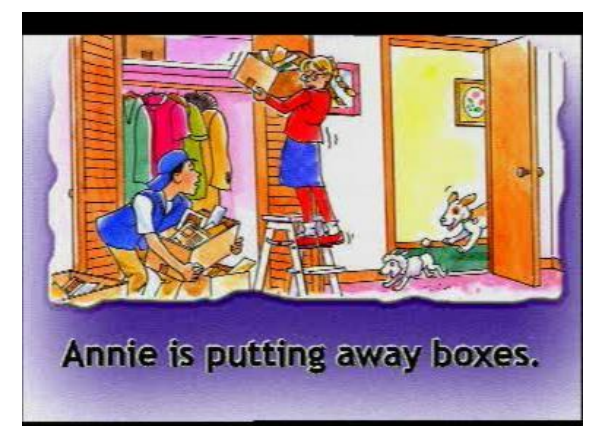

E. Picture cues and input passage for the reconstruction task (An example from the form used in the 2 nd treatment session)

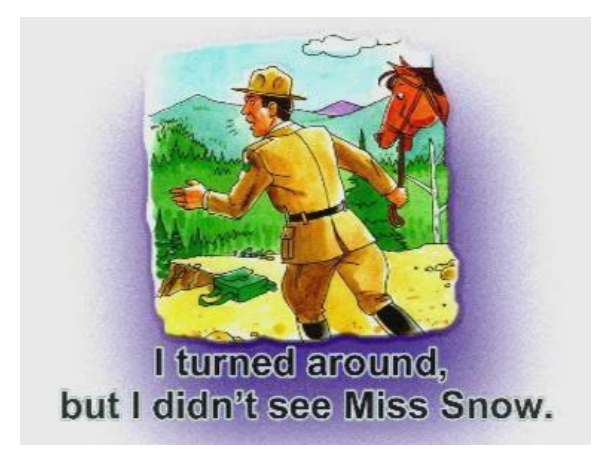

F. Picture cues and input passage for the reconstruction task (An example from the form used in the 3rd treatment session)

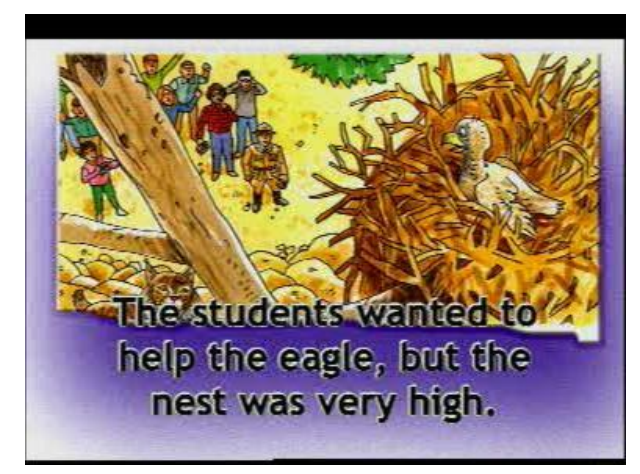

\section{REFERENCES}

[1] Anderson, J. (1996). The architecture of cognition. Cambridge, MA: Harvard University.

[2] Bloor, M., Bloor, T., Forrest, R., Laird, E. \& Relton, H. (1970). Objective tests in English as a foreign language. Macmillan education limited: Basingstoke and London.

[3] Bygate, M. (1999). Quality of language and purpose of task: Patterns of learners' language on two oral communication tasks. Language Teaching Research, 3, 185-214.

[4] Celce-Murcia, M. (1991). Grammar pedagogy in second and foreign language teaching. TESOL Quarterly, 25, 459-480.

[5] Clark, H., \& Clark, E. (1977). Psychology and language: An introduction to psycholinguistics. New York: Harcourt Brace.

[6] Colina, A.A. \& Garcia-Mayo, M.P. (2007). Attention to form across collaborative tasks by low-proficiency learners in an EFL setting. In Garcia Mayo (Eds.), Investigating tasks in formal language learning (pp. 91-117). Multilingual Matters, Clevedon, England.

[7] de Bot, K. (1996). Review article: The psycholinguistics of the output hypothesis. Language Learning, 46, 3, 529-555.

[8] De la Fuente, M. (2006). Classroom L2 vocabulary acquisition: Investigating the role of pedagogical tasks and form-focused instruction. Language Teaching Research, 10, 3, 263-295. 
[9] DeKeyser, R. \& Sokalski, K. (1996). The differential role of comprehension and production practice. Language Learning, 46, 613-642.

[10] Ellis, R. (2006). Current issues in the teaching of grammar: An SLA perspective. TESOL Quarterly, 40, 83-107.

[11] Garcia Mayo, M.P. (2002). The effectiveness of two form-focused tasks in advanced EFL pedagogy. International Journal of Applied Linguistics, 12, 2, 156-175.

[12] Geeslin, K. (2006). Task design, discourse context and variation in second language data elicitation. Studies in Second Language Acquisition, 24, 419-450.

[13] Izumi, S. (2002). Output, input enhancement, and the Noticing Hypothesis: An experimental study on ESL relativization. Studies in Second Language Acquisition, 24, 541-77.

[14] Izumi, S. (2003).Comprehension and production processes in second language learning: In search of the psycholinguistic rationale of the output hypothesis. Applied Linguistics, 24, 2,168-196.

[15] Izumi, S., \& Bigelow, M. (2000). Does output promote noticing and second language acquisition? TESOL Quarterly, 34, 239278.

[16] Izumi, S., Bigelow, M., Fujiwara, M., \& Fearnow, S. (1999). Testing the output hypothesis: Effects of output on noticing and second language acquisition. Studies in Second Language Acquisition, 21, 421-452.

[17] Izumi, Y. \& Izumi, S. (2004). Investigating the effects of oral output on the learning of relative clauses in English: Issues in the psycholinguistic requirements for effective output tasks. Canadian Modern Language Review, 60, 5, 587-609.

[18] Kim, Y. (2009). The effects of task complexity on learner-learner interaction. System, 37, 254-268.

[19] Klein, W. \& Perdue, C. (1992): Utterance structure: Developing grammars again. Amsterdam: John Benjamins.

[20] Krashen, S. (1985). The input hypothesis: Issues and implications. New York: Longman.

[21] Kuiken, F. \& Vedder, I. (2008). Cognitive task complexity and written output in Italian and French as a foreign language. Journal of Second Language Writing, 17,48-60.

[22] Lyster, R. (2004). Differential effects of prompts and recasts in form-focused instruction. Studies in Second Language Acquisition, 26, 399-432.

[23] Mehrang, F. \& Rahimpour, M. (2010). The impact of task structure and planning conditions on oral performance of EFL learners. Procedia Social and Behavioral Sciences, 2, 3678-3686.

[24] Mennim, P. (2003). Rehearsed oral L2 output and reactive focus on form. ELT Journal, 57, 2, 130-138.

[25] Mennim, P. (2007). Long-term effects of noticing on oral output. Language Teaching Research 11, 3, 265 - 280.

[26] Nassaji, H. \& Tian, J. (2010).Collaborative and individual output tasks and their effects on learning English phrasal verbs. Language Teaching Research, 14, 4, 397-419.

[27] Newton, J. \& Kennedy, G. (1996). Effects of communication tasks on the grammatical relations marked by second language learners. System, 24, 3, 309-322.

[28] Nobuyoshi, J. \& Ellis, R. (1993). Focused communication tasks and second language acquisition. ELT Journal , 47, 203 - 210.

[29] Norris, J., \& Ortega, L. (2000). Effectiveness of L2 instruction: A research synthesis and quantitative meta-analysis. Language Learning, 50, 417-528.

[30] Perdue, C. \& Klein, W. (1993): Concluding remarks. In Perdue, C. (Eds.), Adult language acquisition: Cross-linguistic perspective. Volume 2 The Results (pp. 253-272). Cambridge: Cambridge University Press.

[31] Qin, J. (2008). The effect of processing instruction and dictogloss tasks on acquisition of the English passive voice. Language Teaching Research, 12, 1, 61-82.

[32] Reinders, H. (2009). Learner uptake and acquisition in three grammar-oriented production activities. Language Teaching Research, 13, 2, 201-222.

[33] Robinson, P. (2001). Task complexity, task difficulty, and task production: Exploring interactions in a componential framework. Applied Linguistics, 22, 1, 27-57.

[34] Shehadeh, A. (1999). Non-native speakers' production of modified comprehensible output and second language learning. Language Learning, 49, 627-675.

[35] Shehadeh, A. (2003). Learner output, hypothesis testing, and internalizing linguistic knowledge. System, 31, $155-171$.

[36] Song, M. \& Suh, B. (2008). The effects of output task types on noticing and learning of the English past counter factual conditional. System, 36, 295-312.

[37] Storch, N. (1998 a). Comparing second language learners' attention to form across tasks. Language Awareness, 7, 4, 176-91.

[38] Storch, N. (1998 b). A classroom-based study: Insights from a collaborative text reconstruction task. ELT Journal, 52, 4, 291-300.

[39] Swain, M. (1985). Communicative competence: Some roles of comprehensible input and comprehensible output in its development. In S. Gass \& C. Madden (Eds.), Input in second language acquisition (pp. 235-253). Rowley, MA: Newbury House.

[40] Swain, M. (1995). Focus on form through conscious reflection. In C. Doughty and J. Williams (Eds), Focus on form in classroom second language acquisition (pp. 64-81). New York: Cambridge University Press.

[41] Swain, M. (2005). The output hypothesis: Theory and research. In E. Hinkel (Eds.), Handbook of research in second language teaching and learning (pp.471-483). Mahwah, NJ: Lawrence Erlbaum.

[42] Swain, M. \& Lapkin, S. (1995). Problems in output and the cognitive processes they generate: A step towards second language learning. Applied Linguistics, 16, 371-391.

[43] Swain, M. \& Lapkin, S. (2001). Focus on form through collaborative dialogue: Exploring task effects. In M. Bygate, P. Skehan, \& M. Swain (Eds.), Researching pedagogic tasks: Second language learning, teaching, and testing (pp. 99-118). Harlow, UK: Pearson Education.

[44] Vickers, C. \& Ene, E. (2006). Grammatical accuracy and learner autonomy in advanced writing. ELT Journal, 60, 2, $109-116$.

[45] Yoshimura, F. (2006). Does manipulating foreknowledge of output tasks lead to differences in reading behaviour, text comprehension and noticing of language form? Language Teaching Research, 10, 4, 419-434. 
Shirin Abadikhah is assistant professor of TEFL at the University of Mazandarn, Iran. She received her PhD in applied linguistics from the University of Edinburgh, UK, her M.A. in TEFL from Tarbiat Modarres University, Iran, and her BA in English Translation from Allame Tabatabaei University, Iran. She teaches EFL courses at undergraduate and graduate levels at Mazandaran University. Her main research interests include applied linguistics and second language acquisition.

Foroogh Zarrabi is an MA student in TEFL at the University of Mazandaran, Iran. She has been teaching English in the Iran Language Institute since 2005. Her research interests include TBLT, discourse analysis and form-focused instruction. 